\title{
Using CAP Dimensionality for Service and User Allocation for Optical Access Networks
}

Binti Othman, Maisara; Zhang, Xu; Jensen, Jesper Bevensee; Tafur Monroy, Idelfonso

\section{Published in:}

ACP Technical Digest

Link to article, DOI:

10.1364/ACP.2012.AS3C.5

Publication date:

2012

Document Version

Publisher's PDF, also known as Version of record

Link back to DTU Orbit

Citation (APA):

Binti Othman, M., Zhang, X., Jensen, J. B., \& Tafur Monroy, I. (2012). Using CAP Dimensionality for Service and User Allocation for Optical Access Networks. In ACP Technical Digest (pp. AS3C.5). Optical Society of America. https://doi.org/10.1364/ACP.2012.AS3C.5

\section{General rights}

Copyright and moral rights for the publications made accessible in the public portal are retained by the authors and/or other copyright owners and it is a condition of accessing publications that users recognise and abide by the legal requirements associated with these rights.

- Users may download and print one copy of any publication from the public portal for the purpose of private study or research.

- You may not further distribute the material or use it for any profit-making activity or commercial gain

- You may freely distribute the URL identifying the publication in the public portal 


\title{
Using CAP Dimensionality for Service and User Allocation for Optical Access Networks
}

\author{
M.B. Othman ${ }^{1,2}$, Xu Zhang ${ }^{1}$, J. Bevensee Jensen ${ }^{1}$ and I. Tafur Monroy ${ }^{1}$ \\ ${ }^{1}$ DTU Fotonik, Dep. of Photonics Engineering, DTU, Ørsteds Plads 343, DK-2800 Kgs. Lyngby, Denmark. \\ ${ }^{2}$ Department of Communication Engineering, FKEE, UTHM, 86400 Parit Raja, Johor, Malaysia. \\ mabio@fotonik.dtu.dk; jebe@fotonik.dtu.dk;idtm@fotonik.dtu.dk
}

\begin{abstract}
The usability of carrierless amplitude and phase (CAP) modulation dimensions for service and user allocation for WDM optical access is experimentally demonstrated in a 2X2D-ODMA configuration.

(C) 2012 Optical Society of America

OCIS codes: $060.4080,060.4230,060.0060$
\end{abstract}

\section{Introduction}

Next generation access networks (NGAN) needs to supply multiple users with access to multiple services such as voice, data, images and video while sharing the same physical infrastructure in the fiber to the home (FTTH) network. All-optical 2 dimensional (2D) optical code division multiple access (OCDMA) has been proposed for NGAN for multimedia applications [1] and increased spectral efficiency in FTTH [2]. Due to the limited coding space, incoherent 1 dimensional (1D) optical coding technology (either in time or wavelength domain) is not feasible for future access networks which are required to support a large number of end users. Both 2D and 3 dimensional (3D) encoding techniques require multiple domains to realize optical codes. Therefore, it is difficult to smoothly upgrade the capacity of an access network where 2D or 3D encoders/decoders are employed [2]. In order to overcome this problem the encoder and decoder can be designed in the electrical domain. Orthogonal division multiple access (ODMA) exploring the multiple possible dimensions of carrierless amplitude and phase (CAP) modulation [3] has been proposed for multiple services application. Hybrid OCDMA and wavelength division multiple (WDM) network have been proposed and demonstrated in [4] to significantly improve the system flexibility and performance. Regarding light sources for optical access, directly modulated vertical cavity surface emitting lasers (DM-VCSELs) have emerged as an attractive solution due to the cost effective production and low modulation voltage.

In this paper, we propose what we believe is the first experimental demonstration 2x2D-ODMA configuration in WDM access network. We believe this new concepts can be implemented in WDM networks in an elegant way by utilizing the orthogonal CAP filters are designed in digital domain. Moreover the higher dimensionality ODMA is able to support multiple services without requiring additional domains in the optical link.

\section{Principle of ODMA}

Code division multiple access (CDMA) has been introduced in wireless communication. ODMA can be classified under the CDMA concept, with orthogonality imposed on the set of signals. The ODMA concepts have been proposed for higher dimensionality CAP in bicipital subscriber line (DSL) application [3]. CAP is a multi-dimensional multilevel signal employing orthogonal waveforms; one for each dimension. These waveforms are obtained from frequency domain filters with orthogonal impulse responses. The orthogonal waveforms are generated by using an optimization algorithm (OA) [5]. To avoid inter-dimensional crosstalk, it is vital that the transmitter-receiver (transceiver) filter combinations satisfy the orthogonality or perfect reconstruction (PR) criteria. Fig. 1(a) shows the cross responses of the four orthogonal transceiver filters for four dimensional (4D)-CAP. The transceiver filters combination satisfies the orthogonality or PR criteria. The transmitter is represented by $f_{N}$ and the receiver is represented by $g_{N}$. The impulse only exists at the cross responses of $f_{1}$ and $g_{1}, f_{2}$ and $g_{2}, f_{3}$ and $g_{3}, f_{4}$ and $g_{4}$.

Fig.1(b) shows the scenario of the 2D-ODMA that has been demonstrated in a WDM architecture. There are 2 WDM channels; channel 1 ( $\mathrm{CH} 1)$ represented by filter 1D and 2D, and channel $2(\mathrm{CH} 2)$ are represented by filter 3D and 4D in the central office (CO). From the concepts of OCDMA technique a unique code structure is designed to distinguish different users and services. In this demonstration, we divided the total 4D-CAP into 2 channels and successfully demodulated the signals in the optical network unit (ONU). 


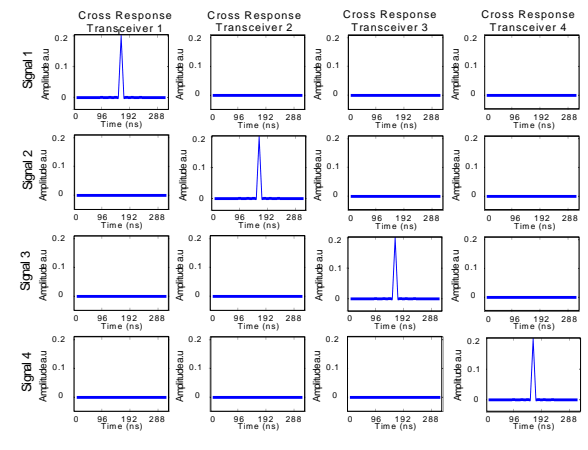

(a)

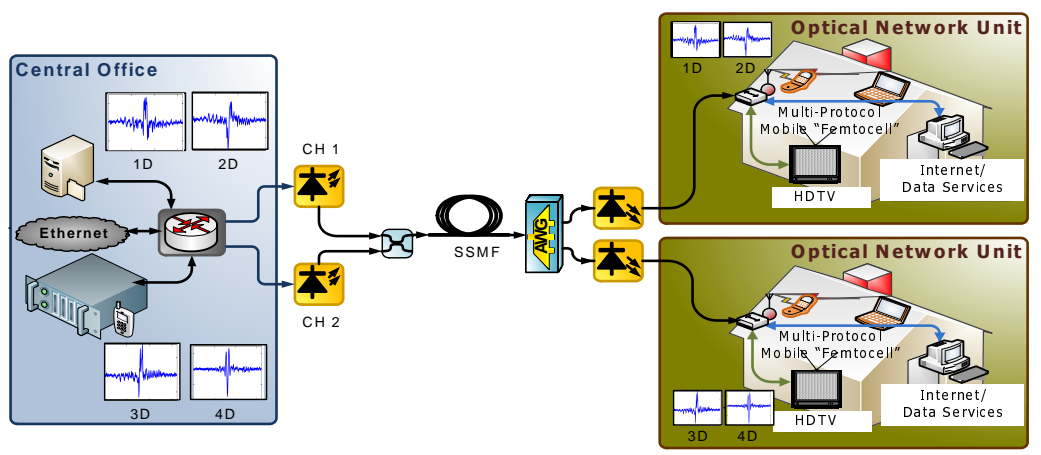

(b)

Fig. 1: 4D-CAP (a) cross responses of transceiver filter and (b) 2x2D-ODMA scenario for WDM system.

Table 1: Relationship of 2x2D-CAP at different L/D

\begin{tabular}{c|c|c|c|c|c|c|c}
$\begin{array}{c}\text { Signal } \\
\text { 2x2D- } \\
\text { ODMA }\end{array}$ & Bits/symbol & $\begin{array}{c}\text { Total } \\
\text { levels }\end{array}$ & $\begin{array}{c}\text { Upsampling } \\
\text { Factor }\end{array}$ & $\begin{array}{c}\text { Bit Rates } \\
(\mathrm{Mb} / \mathrm{s})\end{array}$ & $\begin{array}{c}\text { Bandwidth } \\
(\mathrm{MHz})\end{array}$ & $\begin{array}{c}\text { Spectral } \\
\text { Efficiency } \\
(\mathrm{b} / \mathrm{s} / \mathrm{Hz})\end{array}$ & $\begin{array}{c}\text { Sampling } \\
\text { Rate } \\
(\mathrm{Mbaud})\end{array}$ \\
\hline \hline 2-L/D & 4 & 16 & 12 & 416.67 & 400 & 1.04 & 104.16 \\
\hline 4-L/D & 8 & 256 & 12 & 833.3 & 400 & 2.08 & 104.16
\end{tabular}

\section{Experimental Setup}

Fig. 2 shows the setup implemented in the experiment. An arbitrary waveform generator (ArbWaveGen) with sampling rate of $1.25 \mathrm{GSa} / \mathrm{s}$ is used to generate the 2D-CAP signals. $\mathrm{CH} 1$ is represented by waveforms 1 and 2 and $\mathrm{CH} 2$ is represented by waveforms 3 and 4 . Data in the transmitter is mapped according to the given constellation by converting a number of raw data bits into a number of multilevel symbols (i.e 2-L/D or 4-L/D). Those symbols are upsampled and later shaped (or filtered). The transmitter filters are implemented as fixed finite impulse response (FIR) filters. The 2 VCSELs at $1540.61 \mathrm{~nm}(\mathrm{CH} 1)$ and $1541.01 \mathrm{~nm}(\mathrm{CH} 2)$ with $4.5 \mathrm{GHz}$ bandwidth operating at $4 \mathrm{~mA}$ bias level are directly modulated with the CAP signals. The two signals are combined using a $3 \mathrm{~dB}$ coupler as shown in Fig. 2(a). The signals are propagated through $20 \mathrm{~km}$ standard single mode fiber (SSMF) with a total fiber loss of $6.5 \mathrm{~dB}$. A variable optical attenuator (VOA) is placed after the fiber for bit error rate (BER) measurements. At the receiver, the signals are been seperated into ONU1 and ONU2 by the arrayed waveguide grating (AWG). The signals is directly detected by a photodetector (PD) and stored in a digital storage scope (DSO) with $40 \mathrm{GSa} / \mathrm{s}$ sampling rate for offline demodulation. At the receiver, the inversion of the transmission filter is implemented to retrieve the original sequence of symbols. The symbols are down sampled and demapped before the data can be recovered. Transmission quality is assessed using receiver sensitivity at a BER of $2.8 \times 10^{-3}$, since forward error correction (FEC) techniques may be applied to obtain error free transmission when the 7\% of FEC overhead are taken into account. The bits/symbol, total levels, upsampling factor, bit rates, bandwidth, spectral efficiency and sampling rate relationship of the total 2x2D-ODMA at different levels per dimension (L/D) are listed in Table 1.

\section{Results}

Fig. 3(a) and (b) shows the BER results obtained for 2D-ODMA signals at 2-L/D and 4-L/D at ONU1 and ONU2. The solid symbols represent optical back to back (B2B) and the hollow symbols represent $20 \mathrm{~km} \mathrm{SSMF} \mathrm{transmission.}$ For 2D-2L/D for B2B, the receiver sensitivity at the FEC threshold for ONU1 is $-20.1 \mathrm{dBm}$ and $-19.9 \mathrm{dBm}$ at ONU2. After $20 \mathrm{~km} \mathrm{SSMF}$ transmission, the performance is similar for both RNs with the receiver sensitivity of $-19.6 \mathrm{dBm}$. The signals are successfully demodulated below the FEC limit after $20 \mathrm{~km}$ SSMF transmission. This can be clearly seen from the constellation diagram of 2-L/D at ONU1 and ONU2 in the figure with BER approximately $1 \times 10^{-3}$ after $20 \mathrm{~km} \mathrm{SSMF} \mathrm{transmission.} \mathrm{For} \mathrm{2D-4L/D,} \mathrm{the} \mathrm{power} \mathrm{penalty} \mathrm{is} \mathrm{negligible} \mathrm{between} \mathrm{B2B} \mathrm{and} \mathrm{after} 20 \mathrm{~km} \mathrm{SSMF}$ transmission is observed. The insets show the received signal constellation with BER of approximately $1 \times 10^{-3}$ at 

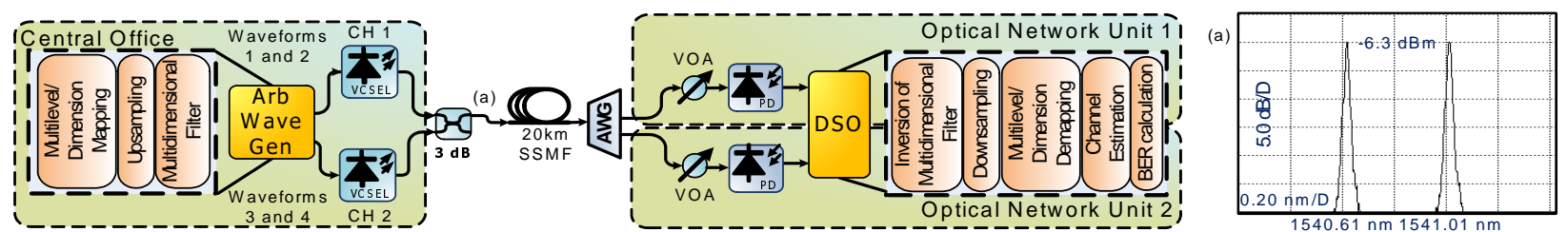

Fig. 2: Experimental setup for 2x2D-ODMA over $20 \mathrm{~km}$ SSMF with DM-VCSELs for WDM architecture.

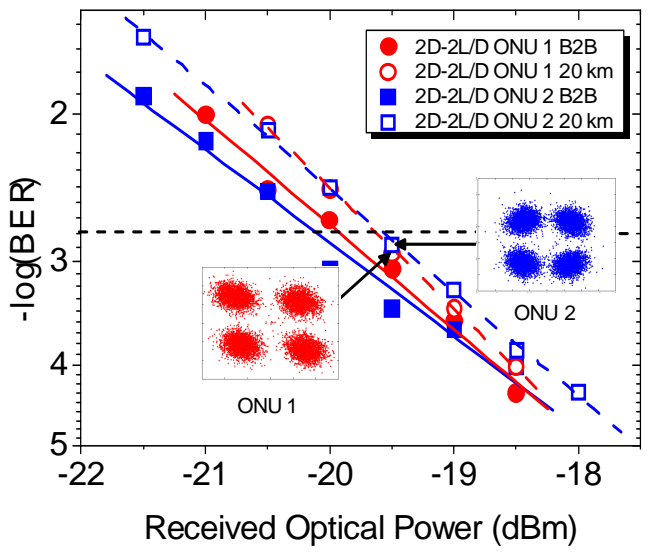

(a)

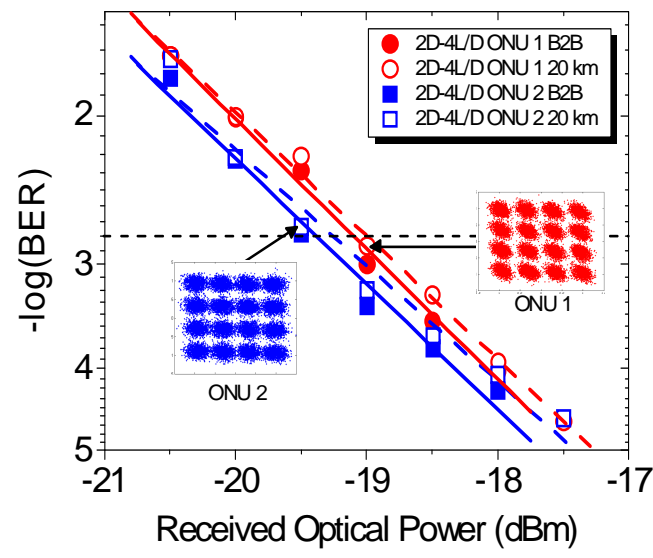

(b)

Fig. 3: Bit error rate (BER) vs received optical power (ROP) (a) 2D-ODMA 2-L/D and (b) 2D-ODMA 4-L/D

ROP of $-19.5 \mathrm{dBm}$ for ONU1 and ONU2 at ROP of $-19 \mathrm{dBm}$ after $20 \mathrm{~km}$ SSMF transmission. Similar performance is observed for $2 \mathrm{~L} / \mathrm{D}$ and $4 \mathrm{~L} / \mathrm{D}$ for $2 \mathrm{D}-\mathrm{ODMA}$.

\section{Conclusions}

We propose and experimentally demonstrate the 2x2D-ODMA/WDM network with DM-VCSEL over $20 \mathrm{~km} \mathrm{SSMF.}$ Both signals are successfully demodulated below the FEC threshold. The spectral efficiency for 4-L/D is $2.08 \mathrm{bits} / \mathrm{s} / \mathrm{Hz}$ with bit rate of $833.3 \mathrm{MHz}$ is presented in this work. The flexibility of the 4D-CAP in dividing the dimensions in the optical fiber systems is successfully demonstrated. This result indicates the prospects of combining the ODMA in WDM network for service and user allocation in next generation access network. Furthermore, the orthogonal FIR filters are designed in digital domain which can be an alternative solution for higher dimensionality OCDMA which requires multiple domains coding.

\section{References}

1. Mikaël Morelle, et. al, "Quality of service differentiation in multimedia 2D optical networks", in $E U$ SIPCO,(2007).

2. FP7 Report, "Survey of next generation optical access system concepts", (2010).

3. A.F.Shalash, K.K. Parhi, "Multidimensional carrierless AM/PM systems for digital subscriber loops" IEEE Transactions on Communication, 47, 11, 1655-1667, (1999).

4. Xu Wang et. al, "Flexible $10 \mathrm{Gbps}$, 8-User DPSK-OCDMA System with 16x16 Ports Encoder and 16-Level Phase-Shifted SSFBG Decoders" in OFC/NFOEC, (2008), paper OMR2.

5. Xiaosong Tang,et. al , "A new digital approach to design 3D CAP waveforms," IEEE Trans. on Comm., 51, 1, 12-16,(2003). 